Erratum

\title{
Erratum: Kim, H., et al. Social Network Analysis of the Jangwi Urban Regeneration Community. Sustainability 2019, 11, 4185
}

\author{
Hwanbae Kim ${ }^{1, *(\mathbb{D})}$, Jae-Kyoung Chung ${ }^{2}$ and Myeong-Hun Lee ${ }^{2, *}$
}

1 Department of Frontier Architectural and Urban Environment Engineering, Graduate School of Hanyang University, 222 Wangsimni-ro, Seongdong-gu, Seoul 04763, Korea

2 Graduate School of Urban Studies, Hanyang University, 222 Wangsimni-ro, Seongdong-gu,

Seoul 04763, Korea; chjk0213@naver.com

* Correspondence: hb1370@hotmail.com (H.K.); mhlee99@hanyang.ac.kr (M.-H.L.);

Tel.: +82-10-7236-1370 (H.K.); +82-2-2220-4418 (M.-H.L.)

Received: 21 April 2020; Accepted: 22 April 2020; Published: 29 April 2020

The authors would like to make the following corrections about the published paper [1]. The changes are as follows:

(1) Replacing Figure 6. Comparison of the network in 2018:

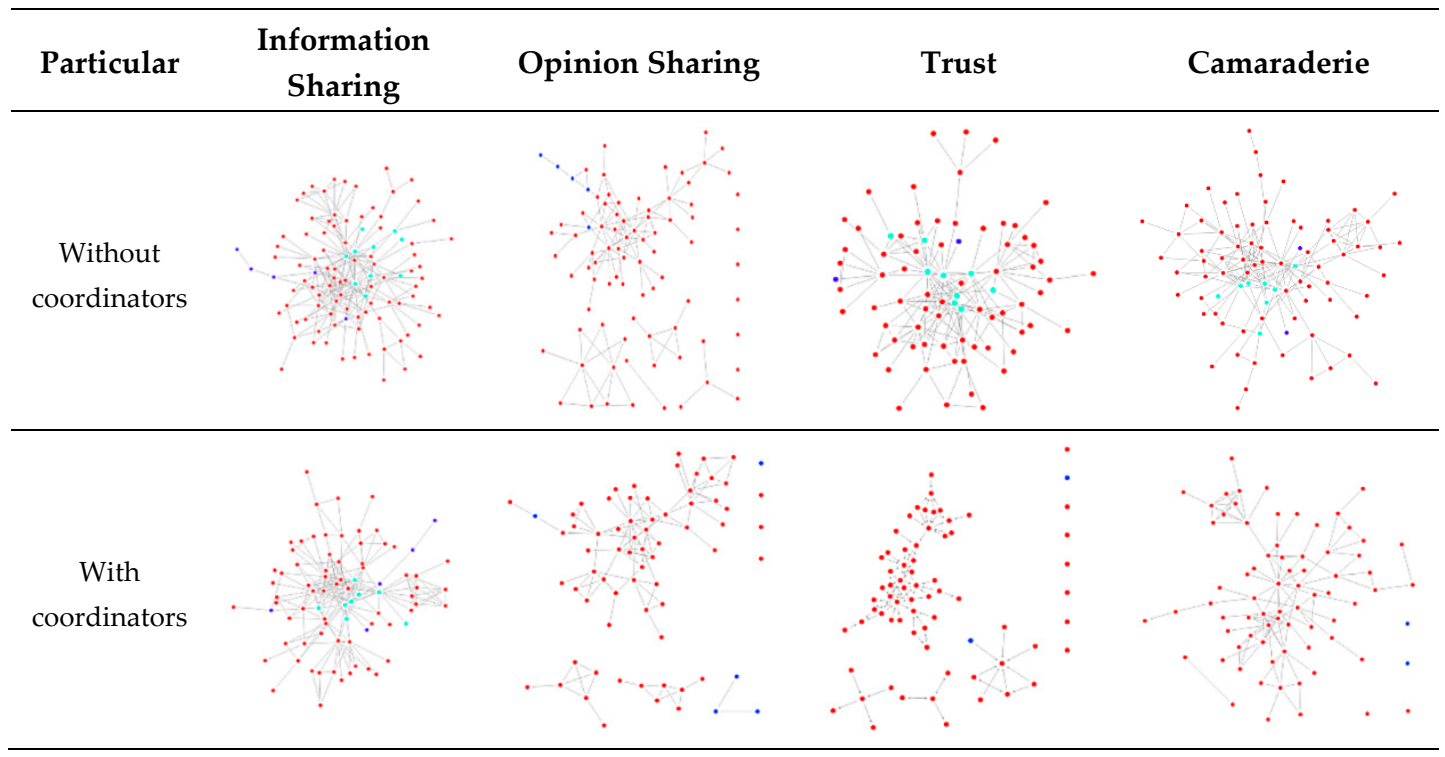

Figure 6. Comparison of the network in 2018.

with 


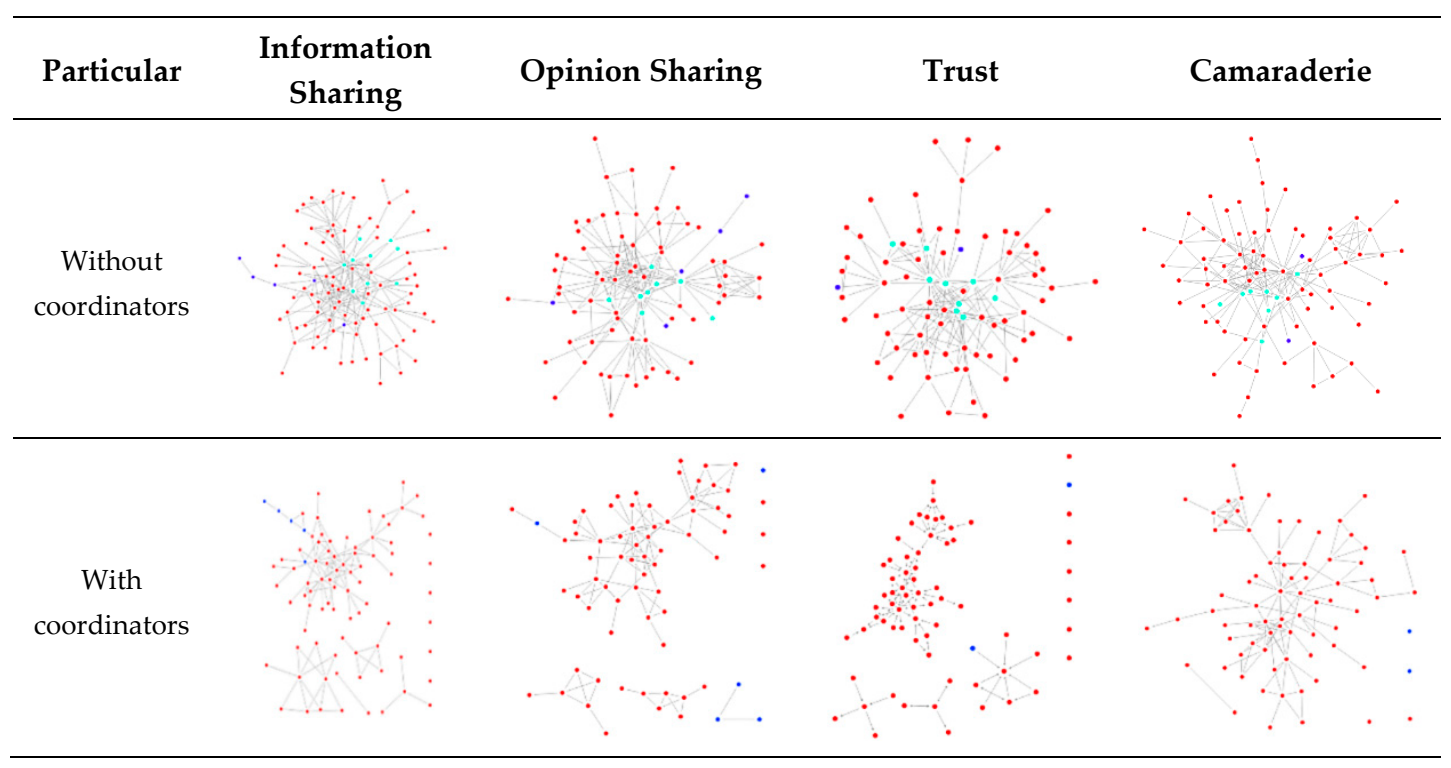

Figure 6. Comparison of the network in 2018.

\section{Reference}

1. Kim, H.; Chung, J.-K.; Lee, M.-H. Social Network Analysis of the Jangwi Urban Regeneration Community. Sustainability 2019, 11, 4185. [CrossRef]

(C) 2020 by the authors. Licensee MDPI, Basel, Switzerland. This article is an open access article distributed under the terms and conditions of the Creative Commons Attribution (CC BY) license (http://creativecommons.org/licenses/by/4.0/). 